\title{
El evangelio de la fe y de la justicia
}

\section{Antonio González, Universidad Rafael Landívar,}

Guatemala.

Con frecuencia se escucha decir a muchos cristianos en el llamado tercer mundo que los tiempos del Exodo ya han pasado, y que ahora nos encontramos en el tiempo más parecido al de Job o al del Eclesiastés'. Con ello se quiere indicar que las esperanzas en unas rápidas transformaciones sociales, destinadas a aliviar la situación de millones de personas empobrecidas, se han ido difuminando en el horizonte. Es como si no hubiera ya esperanzas al alcance de la mano, y hubiera que seguir denunciando que los inocentes como Job siguen sufriendo y que es necesario mantener, como el Qohélet, una mirada crítica sobre el mundo, por más que esa mirada crítica ya no pueda anunciar una pronta transformación social, que vaya a acabar con la injusticia.

No quisiera negar la importancia que el libro de Job o el del Eclesiastés siguen teniendo hoy para el cristiano. Sin embargo, el olvido de la perspectiva del Exodo puede constituir un grave error para aquellos cristianos conscientes de que su fe está de algún modo remitida al problema de la justicia social en el mundo. No se trata simplemente de que el libro del Exodo tenga en todas las épocas una relevancia capital para acceder al núcleo de la fe cristiana y de su contribución a la justicia social. Lo que sucede, además, es que la perspectiva antes mencionada acepta demasiado rápidamente la idea desesperanzada de que las alternativas a la injusticia masiva de este mundo se sitúan en un lejano fuluro.

1. No cansaré al lector con referencias bibliograficas. El investigador que las necesile. podrá encontrarlas en mi estudio titulado Teologia de la praxis evangélica (Santander, 1999). El especialista no dejará de percibir en este texto la presencia de los trabajos de exegetas y télogos biblicos como N. Lohfink. J. H. Yoder. J. Driver. R. Pesch, J. Mateos y G. Lohfink. 
"La esperanza", decía Monseñor Romero, "scrá pronto una rcalidad". Los liracasos de cierlos grupos políticos, de cierlos sistemas cconómicos o de ciertos personajes públicos de ninguna manera anulan, desde la perspectiva bíblica, la cercania de esa realidad. Y no se trata de ninguna manera de convertir la esperanza cristiana en una promesa de ultratumba, en una actitud existencial o en un sentimiento consolador. La esperanza en una superación efectiva y real de la injusticia social no cs. desde el punto de vista bíblico, una esperanza para el luturo. Es una esperanza para hoy, rcalizable en el ahora en que estas líneas se escriben o se leen.

La tendencia a situar las esperanzas en un futuro lejano y a refugiarse en una crítica más o menos desesperanzada del presente no sólo introducen demasiadas "raíces de amargura" (Hb 12, 15) en la comunidad cristiana, sino que también rellcjan, con toda probabilidad, una mala comprensión del mensaje bíblico sobre la le y la justicia. Nadie avanza si no aprende de sus errores; y nadie aprende de sus crrores si nunca admite tenerlos. Para que los cristianos de hoy podamos avanzar en el camino de la fe y de la justicia es muy necesario que aprendamos de los crrores del pasado. Y para eso nada mejor que preguntarnos de nuevo. con cl candor de quien codavía puede aprender $(\mathrm{M} 18,3)$, qué es lo que la fe cristiana dice y aporta al problema de la justicia social.

\section{I. "Creyó Abraham y le fue contado como justicia"}

En ocasiones, la relación entre la fe cristiana y la justicia social se ha planteado de una forma puramente extrínseca y moralista. El cristiano, por el hecho de serlo. tendría que comportarse élicamente, y este comportamiento ético incluiría el compromiso con todas las causas justas de la humanidad. Cuando se descubre que esto no hace nada más que enunciar obligaciones universales de todos los seres humanos, sin aclarar lo específico de la fe, se busca convertir al Jesús histórico en un modelo insigne de dedicación a la lucha universal por la justicia, sin que de nuevo quede muy claro en qué consiste lo específico de la contribución cristiana a esa lucha.

En realidad, la vinculación entre la fe y la justicia es mucho más intrínseca y radical que cualquier obligación ética universal. De hecho, la Escritura, además de reconocer las obligaciones éticas universales, también cuestiona la capacidad que cualquier moralismo, aunque sea un moralismo políticamente correcto, pueda tener para cambiar efectivamente el mundo. Desde el punto de vista bíblico. la relación entre la fe y la justicia constituye un evangelio, una buena noticia, que irrumpe en un mundo de opresión, abriendo un camino de justicia que ese mundo, por sí mismo, apenas podía atisbar. La fe cristiana no sólo afirma que existe ya hoy un camino hacia la justicia, sino que afirma que ese nuevo camino, aunque es imposible para los seres humanos, por muy morales que sean, es sin embargo, posible para Dios (Mc 10, 27). 
La buena nueva de la relación intrínseca entre la fe y la justicia salta a la vista desde las primeras páginas de la Escritura, cuando se nos narra la historia de Abraham, y se afirma que éste "creyó a YHWH, el cual se lo reputó como justicia" (Gn 15,6). Si leemos este texto desde una perspectiva estructural, situándolo en su contexto canónico, aparece claro que no estamos aquí ante un acontecimiento que sea relativo solamente a Abraham como individuo, y que pucda ser reducido a interpretaciones existenciales o intimistas. Estamos ante un hecho que, desde el punto de vista bíblico, es decisivo para toda la historia de la humanidad, y para el plan de Dios con ella.

El libro del Génesis, a lo largo de nueve capítulos (Gn 3-11), nos presenta un panorama sombrío sobre la historia humana. El texto no pretende ser simplemente histórico o etiológico, sino que quiere hablar sobre el presente. Por eso, la historia que comienza con el pecado de Adán termina en el presente de los posibles redactores del texto: en la torre de Babel, símbolo de los grandes imperios opresores como Babilonia. Menos pretensiones historiográficas tiene, si cabe, la historia de Adán, en la cual el mismo protagonista ostenta un nombre que nos pretende representar a todos nosotros: se llama precisamente adam, es decir, "ser humano".

La historia de Adán es la historia de todo ser humano, y esa historia se actualiza y se plasma en las grandes estructuras de opresión, encarnadas en el tcxto por los grandes imperios de la antigüedad. Si en lugar de la torre de Babel ponemos a los grandes rascacielos con los que el sistema capitalista mundial muestra físicamente su poderío, y si en lugar de Adán nos ponemos todos y cada uno de nosotros, nos habremos acercado bastante a lo que el texto nos quiere transmitir, y por tanto, también a lo que la historia de Abraham significa para nuestro presente.

Y es que Abraham, a diferencia de Adán, creyó en la promesa de Dios. Adán prefirió creer en la palabra de la serpiente, la cual promete a los seres humanos ser como dioses, comiendo de los frutos, buenos y malos, de sus propias acciones $(\mathrm{Gn} 3,5)$. Así como el Dios creador hace todas las cosas buenas (Gn I, 31). el ser humano ("Adán") podŕa ser como Dios, haciéndose bueno a sí mismo. mediante los frutos de sus propias acciones. Sin embargo, quien quiere justilicarse a sí mismo disfrutando de los frutos de sus propias acciones no sólo no se hace como Dios, sino que se hace un esclavo de aquellas criaturas ("serpientes") que, poniéndose en el lugar de Dios, pretenden garantizarnos una correspondencia entre nuestra praxis y sus resultados. El resultado es la idolatría y la injusticia generalizada, dos caras de la misma moneda según el pensamiento bíblico.

1) Quien quiere justificarse a sí mismo por los frutos de las propias acciones. ya no puede ver a Dios más que como un enemigo, cuyo juicio sobre la propia praxis ha de ser temido (Gn 3. 8-10). Una vez embarcados en esta lógica, los seres humanos no pueden menos que ofrecer a la divinidad los resultados de su 
propio trabajo, por más que Dios nunca les haya pedido tales sacrificios. Es difícil ser más crítico respecto al origen de la religión institucionalizada (Gn 4, I-5). La alternativa a la esclavitud religiosa puede ser algún intento renovado de endiosarse uno mismo, uniéndose a la divinidad y produciendo "superhombres", por más que tales intentos sean ridículos no sólo frente al Dios creador, sino liente a las simples fuerzas de la naturaleza (Gn 6-9).

2) Quien quiere justificarse a sí mismo por los frutos de las propias acciones. tiene necesariamente que utilizar a los demás para producir esos frutos, cayendo en un juego de manipulaciones y acusaciones mutuas, que sólo pueden provocar la descontianza y la opresión de unos seres humanos por otros ( $G n 3,7.11-16$ ). El deseo de autojustificación no conduce más que a la envidia y al asesinato. pucs los frutos de las acciones de los demás ponen en entredicho los propios logros $(\mathrm{Gn} 4,8)$. Y el intento de que los asesinos reciban las merecidas consecuencias de sus acciones, introduce una lógica imparable de venganzas (Gn 4, 25). El Estado, simbolizado en la torre de Babel, puede tratar de monopolizar la violencia, pero el precio es el dominio institucionalizado de unos sobre otros. Sin duda, el que quiere justificarse a sí mismo, busca el poder para producir resultados y la admiración de los demás ante los lrutos obtenidos; pero esto significa que los demás sólo pueden ser para el poderoso súbditos o admiradores. Los estados, con su tendencia intrínseca a divinizarse, no unen, sino que dividen a la humanidad en diversas banderías nacionales y lingüísticas (Gn 11 ).

3) Quien quiere justificarse a sí mismo por los frutos de sus propias acciones. pone todo el mundo que lo rodea al servicio de una loca carrera por producir resultados, lo cual solamente puede provocar la alienación humana en el trahajo y la destrucción de la tierra entera. Paradójicamente, el último resultado obtenido en esa loca carrera de autojustificación no es otro que la muerte (Gn 3, 17-19).

Tras esta descripción sombría de los diversos aspecios de la injusticia humana, frente a Dios, frente a los demás y frente a la tierra misma, la Escrilura nos presenta la elección de Abraham. De hecho, la narración de cada uno de los peciados humanos ha ido acompañada siempre de una palabra de gracia y de misericordia por parte de Dios (Gn 3, 21; 4, 15; 9, 15).Tras la narración sobre la torre de Babel, no aparcce una palabra de gracia especílica, porque la palabra de gracia no es otra que la elección de Abraham y, con ella, el inicio de la historia de la salvación, presentada en el resto de la Biblia.

En una mentalidad dominada por cierto universalismo filosofante. la particularidad de la clección de Abraham no deja de plantear ciertos problemas. Algunos quisieran que Dios eslableciera unos principios morales o unas normas religiosas. que lodas las personas podrían encontrar por sí mismas, en lodas las culturas, y a cllo se reduciría la acción salvífica de Dios. La particularidad de la clección divina, y la particularidad del pastor nómada elegido, son para muchos 
un cscándalo. Sin embargo, el pensamiento biblico es en este punto enormemenic unánime y coherente: el ser humano no puede volver por sí mismo al paraíso (Gn 3, 23-24), precisamente, porque esa vuelta al paraíso sería un resultado de sus propias acciones y no sacaría al ser humano de la lógica infernal y serpentina en la que lo envuelve su pretensión de autojustificación. Precisamente, la particularidad de la elección muestra que la superación delinitiva de la injusticia no es, como la torre de Babel, una obra humana, sino una iniciativa de Dios.

Sin embargo, niingún predestinacionismo, ni ningún pelagianismo dan cuenla cabal del signilicado de la elección de Abraham. Y es que en esa elección no está en jucgo el problema de la salvación individual, sino el problema de la respuesta divina a un inundo dominado por la injusticia, por la opresión y por el al'ín de poder. Por eso mismo, la particularidad de la elección no pierde de vista la perspectiva universal: "por (i", le dice YHWH a Abraham, "se bendecirán todos los linajes de la tierra" (Gn 12,3). El mismo nombre "Abraham", que Dios le impone, alude a esta dimensión universal de su elección $(G n 17,5)$. En el pensamiento bíblico. la particularidad de una elección está al servicio de un designio que alañe a todo el género humano. Por eso mismo, Ja historia de los patriarcas sc inserta en la historia más amplia de toda la humanidad, dentro de la cual adquicic su sentido. Pablo apurará hasta el extremo esta idea, cuando afirme que incluso el fracaso en la elección cumple una función a favor de toda la humanidad (Ro 9-11).

La particularidad de la elección significa, por de pronto, una ruptura con una humanidad regida por la injusticia: "vete de tu tierra, de tu patria y de la casa de tu padre a la tierra que yo te mostraré" (Gn I2, 1). Y Abraham abandona Harán, el centro del culto lunar, y se pone en camino hacia lo desconocido. Cualquier solución al problema de la injusticia que busque y oblenga el aplauso de las mayorías tiene algo de sospechoso (Lc 6, 26). Pero esta llamada a la ruptura no conduce a Abraham a la soledad o al individualismo. Al contrario, la vocación de Abraham tiene por contenido la promesa de un pueblo y de una tierra: "de ti harć un pucblo grande y tc hendeciré" $(\mathrm{G}$ 12,2). De ahí la importancia cupilal de la descendencia: "mira al cielo y cuenta las estrellas, si puedes contarlas... así scrí tu descendencia" (Gn 15. 5).

Con esto tocamos un nervio de la concepción biblica de la salvación. La altcrnativa de Dios a la injusticia pasa por la formación de un pucblo distinto clegido de entre los pueblos de la tierra. Para formar ese pueblo, a Abraham no sc le piden primeramente grandes obras morales o políticas, sino ante todo la le en cl Dios que lo llama. Si la injusticia, desde el punto de vista bíblico, tiene su raíz última en la falta de fe de "Adán", la historia de la justicia se inicia allá donde alguicn creyó a Dios, y no a la serpiente. Abraham creyó y se le contó como justicia (Gn 15,6). No se trata, obviamente, de una fe puramente individual o interior, ajena a la praxis humana: es más bien una fe que ponc a 
Abraham en marcha con toda su familia. Precisamente, esta fe es la que posibilita una praxis nueva en la historia: frente a la idea, propia de los pueblos semitas, de que Dios exige el sacrificio del hijo primogénito, Abraham no sacrifica a Isaac. La fe no sólo permite a Abraham la disponibilidad para perder lo más querido, sino también la ruptura con las convenciones religiosas de su entorno. Sin la fe no es posible la ruptura, y sin la ruptura no hay novedad en la historia. No sin razón dirá Pablo que la verdadera filiación de Abraham, la que nos hace iniembros del pueblo elegido, no es biológica, sino de fe (GI 3. 7).

En delinitiva, la injusticia que se plasma últimamente en los sistemas imperiales de poder y de prestigio tiene su raíz última en la falta de fe del ser hurnano ("Adán"), empeñado en alcanzar la propia justificación. Frente a ella, la nueva justicia que Dios introduce en la historia arranca de la fe de un pequeño grupo de nómadas, situados al margen de los grandes estados de su tiempo. Ambos factores, el poder imperial y el pueblo de Abraham, constituyen los dos protagonistas que se enfrentan en el relato del Exodo. El imperio egipcio ha esclavizado a los descendientes de Abraham. En este enfrentamiento surge el modelo bíblico para la liberación de la injusticia.

\section{2. "Nuestra justicia será poner en práctica estos mandamientos"}

El Exodo constituye el centro de la fe de Israel. Ningún otro texto sapiencial, por importante que sea, puede ponerse en el lugar de lo que constituye el núcleo de la confesión de fe para un israelita: "Mi padre era un arameo errante, y bajó a Egiplo, y residió allí siendo unos pocos hombres, pero se hizo un pueblo grande, lucrte y numeroso. Los egipcios nos maltrataron, nos oprimieron y nos impusieron dura servidumbre. Nosotros clamamos a YHWH, Dios de nuestros padres, y YHWH escuchó nuestra voz, vio nuestra miseria, nuestras penalidades y nuestra opresión, y YHWH nos sacó de Egipto con mano fuerte y brazo extendido, con gran terror, con señales y prodigios. Y nos trajo a este lugar y nos dio esta tierra, tierra que mana leche y miel" (Dt 26, 5-9).

Lo primcro que llama la atención en estos relatos es la clara vinculación que la le de Israel establece entre la miseria y la responsabilidad humana. La pobreza no es presentada como una fatalidad, como un designio divino o como una responsabilidad de los pobres. La pobreza es asociada directamente con la opresión de unos seres humanos por otros. Los egipcios esclavizan brutalmente a los isriclitas (Ex I, 8-14). Algo muy coherente con los relatos del Génesis. Y algo que conviene ser recordado en unos tiempos donde tanto los "conservadores" como los "progresistas" tienden con demasiada facilidad a aceptar los poderes y las reglas que rigen estc mundo. En cualquier caso, lo que claramente no encaja con las conccpciones usuales "conservadoras" o "progresistas" es la alternativa a la opresión que el relato del Exodo propone como querida por Dios. Veamos esto con más dctenimiento. 
Es interesante observar que el libro del Exodo, antes de presentarnos la alternativa de YHWH a la opresión, nos pone primero delante de diversas alternativas más obvias y más usuales a la misma. Pero nos muestra la relativa ineficacia de todas ellas.

1) En primer lugar, tenemos la "resistencia pasiva" de las parteras israelitas, que dan largas a la orden faraónica de eliminar a los varones recién nacidos. Es una vía de resistencia muy frecuente entre los pueblos secularmente oprimidos ("cómo no, patroncito, ahorita mismo lo vamos a hacer..."). Sin embargo. la actitud de las parteras no cambia en absoluto la política del faraón, quien encomienda la tarea genocida a los propios egipcios (Ex 1, 15-22).

2) En segundo lugar, tampoco parece ser muy efectiva lo que podemos Ilamar la "caridad individual". La hija del faraón liene misericordia del bebé hebreo abandonado sobre las aguas del Nilo. Esta actitud, coherente con la ética del Antiguo Oriente (¡no sólo de Israel!), de socorrer "al huérfano y a la viuda", puede ser providencial por lo que se refiere a la tarea que Moisés desempeñará en el futuro. Pero, por sí misma, la caridad de la hija del Caraón no cambia la situación de los hebreos, que siguen siendo oprimidos.

3) Tampoco cambia nada, en tercer lugar, el recurso de Moisés a la violencia contra los opresores. Sin duda, el texto es muy realista al presentar la violencia de Moisés como una respuesta a la violencia primera del sistema: Moisés mata al egipcio, que golpea a un hebreo. Pero la violencia no sólo produce la desconfianza de los mismos oprimidos hacia su presunto liberador, sino que, además, desencadena la reacción violenta del sistema contra Moisés, quien se tiene que exiliar (Ex 2, I1-22). Al final, la situación de los oprimidos no ha cambiado en absoluto, como el texto nos lo dice con claridad (Ex 2, 23).

4) Cabe pensar, entonces, en una vía más "moderada", la de las negociaciones, que buscan una "concertación" con los opresores. Moisés y Aarón inician el diálogo con el faraón. Al parecer, no piden grandes transformaciones del siste$\mathrm{ma}$, sino solamente una leve mejora en las condiciones laborales de los hebreos. En concreto, Moisés y Aarón solicitan tres días festivos (Ex 5, 3). Sin embargo, la negociación fracasa y el faraón endurece las condiciones laborales de los hebreos. Los trabajadores israelitas no pueden menos que sentirse traicionados por sus representantes (Ex 5, 1-6, 1).

5) Finalmente, la historia de las plagas nos muestra un imperio egipcio a punto de colapsar. Enfrentado con Dios, con sus trabajadores y con el medio ambiente natural, el sistema entra en una plena crisis. El faraón se halla desprestigiado, pero obstinado en mantener la opresión (Ex 10, 28). Moisés. en cambio, goza de gran autoridad entre los mismos egipcios y sus dirigentes (Ex 11, 3). Podría pensarse que habla llegado el momento en que Moisés tomara el poder e hiciera los cambios necesarios en el sistema. La historia bíblica ya nos ha pre- 
sentado el precedente de un hebreo en el gobierno del imperio: José. Como primer ministro del taraón, José había conseguido que el Estado se apropiara de los medios de producción, posibilitando así la superación del hambre en un momento de crisis (Gn 47, 13-26).

Sin embargo. la propucsta central del Exodo es muy distinta. Dios no prelendia sentar a Moisés en el palacio del faraón, sino crear un comunidad alternativa. en la periferia del sistema. Y esa comunidad no es otra que el pueblo de Israel, establecido en la ticrra prometida. No se trataba de una transformación ni de una reforma del sistema, sino de la creación por parte de Dios. de algo radicalmente nucvo en la hisloria: una comunidad alternativa, en la cual no se han de repetir las injusticias que tienen lugar en los sistemas opresivos, que imperan sobre el mundo. Veamos esto más despacio.

a) En primer lugar, como en el caso de Abraham, estamos ante una salida. antc una ruptura, ante un éxodo. La propuesta bíblica tiene poco que ver con la idea de una toma del poder político para transformar la sociedad desde el palacio del faraón. Este tipo de soluciones suelen encomendar la superación de la injusticia a algún tipo de elite o de vanguardia. la cual ejerce el poder el nombrc de los oprimidos, inientras promete que en el futuro desaparecerá loda opresión. En cambio, la solución bíblica inicia ya la construcción de una nueva sociedad, y esa construcción no se encomienda a un nuevo grupo de poderosos, sino que comicnza desde los inismos oprimidos, que inician desde ahora mismo una nueva forma de sociedad, en la periferia del sistema. Es la radicalidad de crear algo totalmente nuevo: un sistema alternativo. Precisamente porque la novedad es mayor, la ruptura y el riesgo son mayores.

h) En segundo lugar, la nueva sociedad respondc a una iniciativa de Dios, y no es un simple resultado de los esfuerzos humanos: "no es por tu justicia por lo que YHWH lu Dios le da en posesión esa tierra" (D1 9,6). La imagen de Dios abriendo las aguas del mar para que pasen los israelitas alude al Dios creador, que separa las aguas iniciales para hacerle un lugar al mundo habitable (Gn I, 67). $Y$ es que la radicalidad de la idea bíblica de creación no procede de especulaciones lilosóticas, sino de la experiencia de que Dios puede crear algo nuevo cn la historia: una sociedad distinta en la cual las injusticias de los imperios no se repiten.

c) La inicialiva de Dios establece, entonces, una diferencia entre éste y todos los demás dioses de los demás pueblos. El Salmo 82 presenta a Dios entrando cn la asamblea de los dioses y reprochándoles a éstos que no han sido capaces ic resolver el problema de la injusticia. El monoteísmo bíblico no obedece primeramente a especulaciones filosóficas, sino a la experiencia de que el Dios de Abraham y de Moisés es un Dios capaz de salvar a su pueblo, a diferencia de lodos los ídolos creados por la mano humana. Estos últimos, aunque promelen salvación. no hacen más que crear dependencia, legitimando distintos sistemas 
de opresión. Por eso mismo la nueva sociedad creada por Dios hace que se tarnbaleen los cimientos de la tierra (Sal 82, 5).

d) Si la iniciativa procede de Dios, lo que se le pide a la nueva comunidad cs. ante todo, una te en las promesas de aquél, que les permita ponerse en camino, saliendo del sistema opresor y dejando atrás otras soluciones insuficicntes: "el pueblo creyó, y al oír que YHWH había visitado a los israelitas y había visio su aflicción, se postraron y adoraron" (Ex 4, 31). Sin la fe del pueblo en las promesas de Dios, la liberación radical de la injusticia, propuesta cn el Exodo. no habría tenido lugar.

e) La fe que posibilita ponerse en marcha no es la fe de un individuo, sino la fe de una comunidad concreta. La liberación en Egipto no es posible sin la existencia de una comunidad de fe, capaz de identificar las nuevas propuestas de YHWH con las viejas promesas del Dios de Abraham, de Isaac y de Jacob. reconociendo que se trata del mismo y único Señor (Ex 3, 13-15). La liberación de la injuslicia, en el modelo bíblico. no consistc en la enunciación de grandes principios éticos o políticos. sino en la historia de Dios con una comunidad concreta. que cree en él. que clama a él y que espera en él, desde lo prolundo de la injusticia.

1) Sin embargo. la liberación de la injusticia no sólo presupone una comunidad, sino que también la crea. Y no la crea sobre bases raciales o lingüísticas. sino sobre la iniciativa de Dios. Esta iniciativa es suficientemente alractiva como para atraer a la nueva comunidad a una gran muchedumbre de personas oprimidas, que no son israelitas (descendientes de Israel), pero que, con los israclitas, creen en la iniciativa de Dios. se ponen en inarcha y pasan a lormar un solo y nuevo pueblo (Ex 12, 37-38).

g) Solamente en el contexto de la iniciativa de Dios y de la existencia de una comunidad creyente es posible entender un liderazgo como el de Moisés. Al Inargen de esa iniciativa y sin la existencia de una comunidad creyente, tiene poco sentido identificar a cierlos personajes o movimientos como "nuevos Moisés", destinados por lo general y cuando menos a defraudar a los oprimidos. Sin cmbargo. siluada en el contexto adecuado, la figura de Moisés es especialmente aleccionadora, porque muestra no sólo la necesidad de un liderazgo autóctiono, sino también la necesidad de que ese liderazgo conozca en profundidad tanto la cultura de los oprimidos como la de los opresores. Sin esa doble experiencia, es imposible hablar de "alternativa", pues loda alternativa presupone una dialćclicil entre dos términos. cuya estructura profunda hay que conocer para no repetir, con nuevas lórmulas, aquello mismo que se rechaza.

h) El proyecto de la sociedad alternativa se plasma en una "instrucción" (เorah), en una "ley", destinada a asegurar que no se repita la opresión de Egipto (Ex 23, 9). El sentido de la ley de Israel solamente es comprensible a partir de la 
liberación previa de la injusticia (Dt 6, 20-25). De ahí la introducción de instituciones como el perdón de las deudas cada siete años (Dt 15, 1-6), la prohibición del préstamo con interés (Dt 23, 20-21) o la recuperación de las propias tierras cada cincuenta años ( $\operatorname{l} v 25,8-12$ ). La comunidad de Israel se debla convertir en una tierra de refugio para los esclavos que huyeran de otras naciones (DI 23, 16 17) y los esclavos israelitas debran de ser liberados periódicamente (Ex 21, 111; Lv 25, 25-54; Dt 15, 12-18). Otras medidas estaban destinadas a asegurar una relación adecuada con el medio ambiente, permitiendo el descanso de la tierra cultivada ( $\operatorname{lv} 15,1-7$ ). De este modo, la ley pretende asegurar una nueva forma de vida, en la que ya no habrá más pobres (Di 15,4). "Tal será nuesıra justicia: cuidar de poner en práctica todas estas instrucciones ante YHWH nuestro Dios, como él nos ha mandado" (Dt 6, 25).

i) No se trata de medidas simplemente palernalistas, destinadas a que los poderosos cuiden del huérfano y la viuda, sin abandonar su poderío. Esto ya existía en las culturas del entorno, incluyendo a los grandes imperios opresores. El mismo Hammurabi se jacta, en su famoso código, de cuidar del huérfano y de la viuda. La nueva sociedad creada por Dios está inspirada por un ethos fraternal y altamente igualitario. Por eso, la ley no prevé necesariarnente la existencia de un rey en Israel (Dt 17,4). De hecho, las tribus de Israel vivieron durante unos doscientos años sin monarquía, como una sociedad "segmentaria y acéfala", tal como dirfan los antropólogos. En el caso de introducirse la monarquia, la ley prevé (post factum o no, poco imporla) una estricta división de poderes entre los jueces, el rey, los sacerdotes y los profetas (Dt 16, 18-18, 22). Esto diferencia de forma radical a Israel de las sociedades del entorno, en las cuales se concentraban todos los poderes religiosos y políticos en una sola persona. El poder del rey mismo ha de estar limitado, no sólo en lo malerial (armas y dinero), sino sobre todo en lo formal: el rey está sometido a la ley, y no sobre ella, y por eso la ha de llevar consigo y leer todos los dfas de su vida (Dt 17, 1619). Así, "su corazón no se engreirá sobre sus hermanos" (Dt 17, 20), los demás israelitas.

.j) De esta manera, el pueblo de Israel estaba destinado a convertirse en una sociedad alternativa, puesta por Dios en medio de los demás pueblos, y destinada a llamar la atención de los demás pueblos, atrayéndolos hacia la forma de vida instituida por Moisés: "Miren, como YHWH me ha mandado yo les enseño preceptos y normas, para que los pongan en práctica en la tierra en la que van a entrar para tomar posesión de ella. Guárdenos y practlquenlos, porque ellos son su sabiduría y su inteligencia a los ojos de los demás pueblos, los cuales, cuando tengan noticia de todos estos preceptos, dirán: 'ciertamente esta gran nación es un pueblo sabio e inteligente'. Porque, en efecto, ¿hay alguna nación tan grande que tenga los dioses tan cerca como lo está YHWH nuestro Dios siempre que lo invocamos? $\mathrm{Y}$ ¿qué nación hay tan grande cuyos preceptos y normas sean tan justos como toda esta ley que yo les expongo hoy?" (Dt 4, 5-8). 
Ahora sc hace claro que la necesaria ruplura y separación del pueblo de Israel como un pueblo que contrasta con todos los demás pueblos no signilica un aislacionismo sectáreo, sino una alternativa. $\mathrm{Y}$ justamente siendo distinto, pero sicndo al mismo tiempo una alternativa atractiva, el pueblo de Israel estaba llamado a ser hendición para todas las nacionés.

\section{3. "Todas nuestras justicias son trapo de inmundicias"}

La historia de Israel, tal como está recogida e interpretada en la Escritura, mucstra obviamente un fracaso, al menos parcial, del pueblo en su misión. Corno dice el profeta Isaías: "concebimos, tuvimos dolores de parto, dimos a luz vicnto; ninguna liberación hicimos en la lierra, ni caycron los moradores del mundo" (Is 26, 18). Posiblemente, muchas personas comprometidas con la justicia social en los últimos años han sentido en algún momento esto mismo. Sin duda. muchos proyectos pasados de justicia social no pretendían otra cosa que tomar el palacio del laraón, para instalar allí al partido correcto. En este sentido. no lueron proyectos suficientemente radicales, por mucho que estuvieran adornados con la panoplia de la revolución. Pero incluso un proyecto radical como el dc Israel experimentó cl [racaso. Y cso merece una rellexión que nos ayude a no repelir los mismos eitores. De hecho, una buena parte de la teología de los escritos bíblicos no es otra cosa que una reflexión sobre el fracaso de Israel.

Si atendemos al diagnóstico de los profetas, el fracaso de Israel tiene dos climensiones fundamentales: la idolatría que le lleva a sustituir al Dios que le ha sacado de Egipto por otros dioses, y las injusticias internas que impiden al puchlo de Isracl presentarse como alternativa ante los demás pueblos. Aquí es importante tener en cuenta dos cosas. En primer lugar, las críticas de los proletas sc dirigen primeramentc contra las injusticias sociales cometidas dentro del pueblo elegido. A los profetas no les sorprende el hecho de que en Egipto, en Asiria o en Babilonia se cometan injusticias sociales. Esto es algo que se presupone, porque responde a la lógica última de Adán-Babel, frente a lo cual Israel Icnía que ser una altemativa. Lo escandaloso está, precisamente, en que el pueblo que tenía que ser una altemativa cometa las mismas injusticias sociales. haciendo inútil el llamado de Dios. En segundo lugar, no se puede separar la crílica de los profetas a la injusticia social de sus críticas a la idolatría, como si las primeras fueran "actuales" y las segundas meramente "culturales" y ya carentes de actualidad. Desde el punto de vista bfblico, como hemos visto, se trata de dos caras de la misma moneda, porque ambas tienen la misma raíz en la increencia de "Adán", el ser humano.

Esta ccuación entre idolatría e injusticia social es algo que se puede observar con claridad en la historia bíblica sobre la introducción de la monarquía. El ethos igualitario de los israelitas sospecha instintivamente de las formas estatales, porque ellas amenazan con implantar, en medio del pueblo elegido, un pala- 
cio del faraón. La parábola de Jotán expresa con claridad este rechazo: el deseo de gobernar aparece entre aquellas personas que no tienen por sí mismas ninguna cualidad benéfica y sólo pueden hallar reconocimiento haciendo daño a los demás (Jue 9, 7-15). Sin embargo, la presión de los filisteos empuja progresivamente a que los israelitas deseen, después de dos siglos sin Estado, una monarquía "como la de los demás pueblos" (IS 8,5). Obviamente. el deseo de ser como los demás pueblos incapacita para ser una alternativa. El profeta Samuel, en nombre de YHWH, acepta a regañadientes este desen del pueblo, pero no deja de advertir sobre sus peligros. La introducción de la monarquía significa al mismo tiempo un rechazo de Dios, que deja así de reinar directamente sobre su pueblo, y una introducción de desigualdades sociales en el pueblo elegido (IS 8 , I-22). De hecho, la obra histórica deuteronomista presenta a los reyes de Israel y de Judá como los principales responsables tanto de la idolatría como de las injusticias sociales. Es la dinámica que conduce no sólo a la división del pueblo elegido en dos estados, sino también al hundimiento definitivo de ambos trente a los grandes imperios de Asiria y de Babilonia.

Sin duda. la experiencia monárquica no sólo deja en Israel un mal sabor de hoca. sino también cierlos modelos con los que formular una esperanza hacia el luturo. El reinado excepcional de David, pecador pero nunca idólatra, ayuda a lormular la visión de un nuevo tipo de liderazgo, en la figura de un "hijo de David". Pcro, sobre todo, el mal reinado de los reyes de Israel y de Judá lleva a lormular el deseo de que un día, en el luturo, Dios mismo volverá a reinar dircctamente sobre su pueblo. Es lo que expresa, por ejemplo, el oráculo del profeta Ezequiel: "mi rebaño ha sido expuesto al pillaje y se ha hecho pasto de todas las fieras del campo por falta de pastor, porque mis pastores no sc ocupan de mi rebaño, porque ellos, los pastores, se apacientan a sí mismos y no apacientan mi rebaño [...]. Así dice el Señor YHWH: Aquí estoy yo, yo mismo cuidaré de mi rebaño y velaré por él [...]. Buscaré a la oveja perdida, tornaré a la descarriada, curaré a la herida, confortaré a la enferma; pero a la que está gorda y robusta la exterminaré; las pastorearé con justicia [.... Yo suscitaré para ponérselo al lirente un solo pastor que las apacentará, mi siervo David: él las apacentará y será su pastor. Yo, YHWH, seré su Dios, y mi siervo David será príncipe en medio de ellos" (Ez 34, 8-24). La idea de un "reinado de Dios" no enuncia simplesnente una utopía universal de justicia, ni mucho menos el diseño de algún nuevo tipo de Estado, sino sobre todo la esperanza en que Dios inismo reine sobre su pueblo por medio de su mesías, estableciendo asi una justicia nueva. Por eso es ante todo "reinado" (mlkt, basileía) y no mero "reino" de Dios.

En algunos pasajes, el Antiguo Testamento analiza de mancra más fina las razones del fracaso de Israel como sociedad alternativa, y este análisis será. linalmentc, completado por el Nucvo Testamento. Según algunos textos, el problema no consiste sólo en una inlidelidad repetida de Israel al plan de Dios, tal 
como estaba expresado en la Torah. Hay algo en el pueblo de Israel, más difícil de limpiar que las manchas de la piel de un leopardo, y que lo inclina siempre al inal (Jer 13,23). El problema está últimamente en el corazón ser del humano. que liene que ser cambiado, porque sin este cambio es imposible realizar la justicia (Ez II, 19; 18, 31; 36, 26). Ahora bien, la ley de Dios, como instrucción para vivir en justicia, no cambia por sí misma el corazón del ser humano. El ser humano puede seguir viviendo con la lógica "adámica" de autojustilicación. De hecho. la ley misma puede ser utilizada para autojustificarse mediantc cl cumplimiento de sus preceptos. Aunque la ley sea un don de Dios, el ser hurnano puede usarla para presentarse a sí mismo como justo, con una justicia lograda por su propio esfuerzo. Bajo esta lógica, la aparente justicia no es más que una más radical injusticia: "somos impuros todos nosotros, como paño inmundo todas nuestras justicias" (Is 64, 5).

Pablo dirá más adelante que la ley, siendo buena, fue utilizada por el pecado (Ro 7. 7-25). Y en los Hechos de los Apósioles se nos dice, de modo expreso que el perdón de los pecados y la verdadera juslicia no se podían alcanzar mediante la ley de Moisés (Hch 13, 38). De hecho, ya el Antiguo Testamento alirma cxplícitamente la insuliciencia de la ley de Moisés para dar vida al pueho (Ez 20.25), y la necesidad de una nueva alianza: "van a llegar días, dice YHWH, en que yo pactaré con la casa de Israel y con la casa de Judá una nueva alianza, no como la que yo pacté con sus padres, cuando los tomé de la mano para sacarlos de Egipto [...]. Pondré mi ley en su interior y sobre sus corazones la cscribiré, y yo seré su Dios y ellos scrán mi pueblo" (Jer 31, 33).

Desde este punto de vista, la realización de la justicia deja de limitarse al recuerdo de las acciones de Dios en el pasado para incluir también la esperanza en una actuación de Dios en el futuro. La fe, en este sentido, no es sólo la fideliclad al camino iniciado por los padres. Ella incluye también la esperanza en c) luturo que Dios tiene preparado a su pueblo, a pesar de los propios pecados. Si la le era necesaria en el pasado para iniciar una ruptura con los sistemas establecidos, lo que se pide ahora del israelita es confiar en el Dios de la historia, y no en los imperios que prometen salvación frente a la amenaza de... otros imperios. Es la fe en Dios lo que puede asegurar la independencia política del pueblo elegido. En cambio, sin esa re, el pueblo no puede subsistir (ls 7, 9). Frente a la realidad hestial de los imperios que se van sucediendo unos a otros. los creyentcs israelitas esperan, en el futuro, el inicio del reinado de Dios sobre su pucblo, el pueblo de los santos del altísimo, y la ruina linal de esoss imperios (Dn 7, 1-28).

Lil necesidad de una nucva alianza y el traslado de la esperanza hacia el luturo no signitican, sin embargo, una sustitución de la estrategia lundamental por la que Dios va a traer justicia a la humanidad. El pueblo elegido conservará, también en el luturo, su lunción de ser una sociedad alternativa, a la cual sc 
sentirán atraídos todos los pueblos. La idea de una peregrinación de las naciones hacia el monte Sión expresa la fascinación que un Israel restaurado podrá ejercer sobre toda la humanidad (So 3, 9-10). Pero esta peregrinación exige la renovación del pueblo elegido, expulsando del mismo a los "fanfarrones" que lo han oprimido (So 3, II). De este modo, quedará un resto humilde de Israel, en el que ya no habrá injusticia (So 3, 12). Sólo entonces será posible la reunión delinitiva de Israel y el cumplimiento de su función frente a todos los pueblos de la tierra (So 3, 20). Así se reformula entonces la fe de Israel: "Sucederá en días futuros, que el monte de la casa de YHWH será asentado en la cima de los montes y se alzará por encima de las colinas. Confluirán a él todas las naciones y acudirán pueblos numerosos. Dirán: 'vengan, subamos al monte de YHWH, a la casa del Dios de Jacob, para que él nos enseñe sus caminos y nosotros sigaınos sus senderos'. Pues de Sión saldrá la ley y de Jerusalén la palabra de YHWH. Juzgará entre las gentes, será árbitro de pueblos numerosos. Forjarán de sus espadas azadones y de sus lanzas podaderas. No se levantará nación contra nación ni se ejercitarán más en la guerra" (Is 2, 1-4; cfr. Miq 4, 1-5).

\section{4. “No hará Dios justicia a sus elegidos?”}

El que la justicia se vaya a realizar en el futuro no significa que la justicia no sc vaya a realizar nunca. Jesús de Nazaret aparece en la historia de Israel proclamando la buena noticia de que el reinado de Dios se ha acercado, nos ha alcanzado y está ya entre nosotros (Mt 3, 2; 12, 28; Lc 17, 21).

Sin embargo, Jesús evila ser proclamado rey (Jn 6, 15). Ya hemos visto córno en el Antiguo Testamento aparecía una cierta ambigüedad ante la institución estatal. Por una parte, la monarquía es una posibilidad prevista por la ley; por olra parle, la institución del Estado es acompañada de graves advertencias por parte de Samuel. Una vez que la monarquía se hunde tras el desastre del año 587 a. C., la restauración de Israel en los libros de Ezequiel, Esdras, o Nehemías no parece prever la reaparición de un Estado independiente, sino solamente la existencia de una zona religiosa autónoma centrada en el templo. Ello no obsta para que fueran valoradas por los judíos figuras como las de José, Daniel o Ester. que desempeñaron importantes papeles políticos en los imperios de turno, no para convertir estos imperios en modelos del reinado de Dios, sino para apoyar, desde sus puestos políticos, la supervivencia del pueblo elegido. Sin embargo, la imposición forzada de la cultura helenista dio lugar a las luchas guerrilleras de los macabeos, que terminaron con la instauración de una nueva monarquía independiente. Sin embargo, resulta obvio que esta monarquía, en modo alguno, podía presentarse como la realización de las esperanzas mesiánicas del Israel. De hecho, la dinastía de los macabeos y de sus sucesores issmoneos termina, como suele suceder con muchos regimenes "liberadores", en liguras nada atractivas como la de Herodes. 
En el tiempo de Jesús y en el inmediatamente posterior, varios grupos podían pensar todavía que el pueblo de Dios necesitaba para su supervivencia y para realizar su misión en la historia la existencia de instituciones estatales, ya lucra conviviendo de un modo "realista" con el imperio romano (saduceos), ya luera realizando una nueva revolución al estilo macabeo (lo cual acabarán propugnando los zelotas). En otros grupos. como los fariseos o los esenios, prevalecía la idea de una existencia no estatal del pueblo de Dios, bien en la lorma de comunidades sinagogales (fariseos) o bien como una separación monástica (Qumrán). Ciertamente, Jesús no espera una realización estatal del reinado de Dios, pues es bien consciente que la existencia del Estado está unida a la dominación y a la opresión: "los jefes de las naciones las dominan como señores ahsolutos y los grandes las oprimen con su poder; no ha de ser así entre ustedes" (Mt 20:25-26). Sin embargo, Jesús propone algo más radical que la simple existencia sinagogal o la retirada monástica. Jesús quiere una transiormación más radical del pueblo de Dios.

El rechazo de la vía estatal no significa, por tanto, ningún espiritualismo por partc de Jesús. Es algo que se puede observar en los relatos de la alimentación Je la multitudes (Mc 6, 30-44; 8, 1-10 y par.). El relalo de la alimentación de la Inultitud judía está situado tras el asesinato del Bautista por Herodes, y presenta a Jesús con los apósıloles "en un lugar desierto" (Mc 6, 31), una probable alusión a la situación del éxodo. Una multitud de gente los sigue, y Jesús se compadece de ellos, y se pone a enseñarle, "pues estaban como ovejas que no tienen pastor" (Mc 6, 34). Al final del día, los discípulos no sienten ninguna solidaridad con la multitud, y le dicen a Jesús: “despídelos para que vayan a las aldeas y puchlos de los alrededores a comprarse de comer" (Mc 6, 36). Sería una lípica reacción cclesiástica: la comunidad de los discípulos de Jesús puede prestar un scrvicio espiritual a la multitud, pero los aspectos "materiales" no conciernen a la iglesia. La respuesta de Jesús contradice frontalmente esta mentalidad: "denles ustedes de comer" (Mc 6, 36). La resolución del problena material de las multitudes es una tarea propia de los discípulos de Jesús. Obviamente, aquí Jesús no está introduciendo ninguna novedad para la fe judía. El centro de la te clel Antiguo Testamento incluye la historia de cómo Dios resuelve la situación material del pueblo esclavizado en Egipto, formando una nueva comunidad en la cual ya no se han de repetir las injusticias vividas bajo el imperio.

Sin embargo, los discípulos no han entendido plenamente lo que Jesús precende. Frente a la idea de que la gente ha de "comprar" su alimento, Jcsús les ha hablado de "dar": "denles ustedes de comer" (Mc 6, 37). Pero los discípulos siguen pensando en comprar, y responden a Jesús: “¿vamos nosotros a comprar closcientos denarios de pan para darles de comer?" (Mc 6, 37). Los discípulos siguen inmersos en la lógica del sistema económico vigente, incluyendo la lógica del Estado romano, emisor del denario de plata, cuyo valor equivalía al jornal de un día. Esta inmersión en la lógica del sistema incluye. por supuesto, una 
comprensión del propio papel de los discípulos, los cuales presuponen que ellos se han de convertir en los mediadores entre el sistema vigente y las necesidades de la gente. Y esto supone, obviamente, un paternalismo u otro tipo de relación vertical entre los discípulos y la multitud. En tiempos más cercanos, los discípulos tal vez habrían dicho: "¿quieres que fundemos ahora una organización no gubermamental para alimentar a esta gente?" $O$ quizás: “quieres que organicemos a esta gente en un sindicato, o en un partido político, para que reclamen a Herodes su derecho a estar bien alimentados?". Los discípulos no sólo siguen en la lógica del dinero, sino también en la lógica del poder. En realidad, no son dos lógicas distintas: el dinero es una cuantificación, cada vez más exacta. del poder.

La respuesta de Jesús a la pregunta de los discípulos rompe con esa lógica. Jesús les pregunta simplemente: "¿Cuántos panes tienen ustedes? Vayan a ver" (Mc 6, 38). Es la nueva lógica que abre Cristo. No se trataba de que los discípulos compraran alimentos para la gente. No se trataba de que ellos se pusieran por encima de la multitud, haciéndose llamar sus benefactores (Lc 22, 25). No se trata tampoco de que los discípulos funden una organización no gubernamental o de que intenten sentarse en el palacio de Herodes para desde allí alimentar a las multitudes. La propuesta de Jesús es más radical: los discípulos han de abrir sus propias bolsas y compartir lo que tienen. No hay que ir a comprar a ninguna aldea cercana, ni hay que esperar a que cambien las circunslancias políticas. Ya desde ahora es posible una sociedad distinta, un sistema económico alternativo, que se inicia entre aquellos que están dispuestos a compartir lo que tienen, recostados sobre la hierba verde, en torno a Jesús (Mc 6, 39-41). El comer recostados era propio de personas libres, no dependientes de amos benefactores. Ahora todos son iguales. La hierba verde es señal de la abundancia. La bendición de Jesús indica que la nueva sociedad solamente es posible mediante la gracia del Dios liberador, que empieza a reinar sobre sus discípulos. La sobra de doce canastos indica que los bienes compartidos fuera de la lógica del sistema son suficientes para alimentar a Israel. El segundo rclato de la alimentación de la multitudes mostrará que esta lógica también es posible para los paganos, que se incorporan a la comunidad de Jesús (Mc 8, 1-10).

De este modo, Jesús renueva y radicaliza el proyecto de justicia del Exodo. Lo renueva, porque convoca de nuevo a la formación de una sociedad alternativa. Lo radicaliza, porque Jesús es consciente que la formación de uná nueval comunidad sólo es posible mediante una adhesión tal a su propia persona que posibilite abandonar las seguridades de la propia posición económica, familiar o religiosa (Mt 10, 37-39). Los episodios en torno al llamado "joven rico" muestran este hecho. No estamos ante un llamado a la vida religiosa, sino ante la insuficiencia de la ley de Moisés para formar la nueva sociedad (Mc 10, 17-20). Sólo el desprendimiento de los propios bienes y el seguimiento de Jesús posibilitan la entrada en la nueva comunidad, sobre la que Dios ejerce su reinado (Mc 10, 21-25). Ciertamente, los ricos están difícultados para entrar en esa nueva 
lógica, pero también incluso los que dicen haberlo dejado todo por seguir a Cristo. Sólo la iniciativa graluita de Dios posibilita, como en el Exodo, la creación de una realidad nueva en la historia: lo que no es posible para los hombres cs posible para Dios (Mc 10, 26-27). Sin embargo, la dificil ruptura con los lazos del sistema no deja a las personas solas ante Dios, sino que da lugar a una nueva comunidad, en la cual se restablecen las relaciones humanas, exceptuando las de lipo paternal (Mc 10, 28-3!; Mt 23, 9). El desafío que esto supone para el sistema signilica que la nueva comunidad estará sometida a las persecuciones (Mc 10, 30-34). La dificultad para entrar en esta nueva lógica la muestra la petición de los hijos de Zebedeo, deseosos de reproducir en la nueva comunidad las estructuras políticas del sistema eslablecido (Mc 10, 35-45). Es necesario que la le posibilite una nueva forma de ver las cosas, liberándonos de la ceguera (Mc $10,46-52$ ). Sin esa fe, no hay nueva comunidad, ni hay por tanto justicia, ni reinado de Dios.

Desde este punto de vista, resulta perfectamente comprensible no sólo el rechazo de Jesús a ser proclamado rey, sino también su actitud frente al imperio romano. Cuando Jesús dice "devuelvan al César lo que es del César y lo de Dios, a Dios" (Mc 12, 17), no está simplemente estableciendo una distinción entre lo político y lo espiritual. En primer lugar, Jesús, al pedirles una moneda romana, ha mostrado la hipocresía de los líderes de Israel: no sólo la hipocresía rcligiosa de poseer una moneda con la imagen idólatra de un emperador divinizado, sino también la hipocresía económica de cuestionar el pago de los itmpuestos al poder invasor al mismo tiempo que se participa y se disfruta del sistema económico que ese poder garantiza. Jesús no dice "den" al César lo que le perlencce, sino "devuélvanselo" (apódote). No se trata de poner de maniliesı que el discípulo tiene dos tipos de obligaciones, unas con el César y otras con Dios. como podría deducirse del verbo "dar". Se trata de devolver al César lo que le pertenece, y esto entraña la devolución de todos los denarios. La pretensión de Jesús es el establecimiento de una nueva comunidad, libre de la lógicá del sistema. lo cual incluye la independencia económica. Devolver a Dios lo que ic pertenece, por otra parte, no significa cumplir ciertas obligaciones religiosas. Esa no eта la idea bíblica, ni la idea de sus oyentes. Desde el punto de vista bíblico, a Dios no sólo le pertenece la tierra y cuanto contiene (Sal 24, 1), sino de un modo especial el pueblo de Israel, que él ha creado, sacándolo de entre los pueblos para convertirlo en un pueblo de su propiedad (Ex 6, 7). De este modo, Jesús no sólo recuerda el proyecto original de Dios para con su pueblo, que él ahora está renovando y radicalizando, sino también la incapacidad de los propios líderes judios para permitir que Israel sea el verdadero pueblo de Dios. Los lalsos pastores han de devolver el pueblo a Dios.

Para lograr esto no basta con retirarse monásticamente al desierto. Pero tampoco liene sentido encaramarse al poder polílico por medio de la violencia. Todo lo contrario, Jesús llama a una renuncia radical a la violencia, hasta el 
punto de pedir el amor a los enemigos (Mt 5, 38-48). Los ejemplos de Jesús son muy concretos, e incluyen una referencia explícita a la costumbre romana de exigir a los pueblos ocupados la ayuda para cargar a lo largo de una milla los bártulos de la tropa (Mt 5, 41). Y es que el uso de la violencia para conseguir el poder no significa ninguna alternativa frente a la lógica imperante en el mundo. Si la delensa de la sociedad alternativa exige hacer lo inismo que hacen los paganos, esa delensa deja de tener sentido, porque deja de haber una alternativa. No se hace más que confirmar la lógica imparable de la violencia, que los estados tratan de monopolizar sin suprimir (Mt 26, 52). Por eso mismo, la sociedad alternativa de Jesús no es una sociedad estatal, ni el reinado de Dios es un rcino como los de este mundo. Pero es un reinado real, en medio de la historia, y precisamente por ello, supone un desafío para los estados de este mundo. Lo que sucede es que las promesas de paz que los profetas habían anunciado para el reinado mesiánico deben comenzar a ponerse en práctica ya desde ahora, porque el reinado mesiánico, desde el punto de vista de Jesús, no es para el futuro, sino que ya ha comenzado. La no violencia de Jesús no es una simple estrategia coyuntural, sino la actitud más coherente con el anuncio de que el reinado de Dios ya se ha iniciado.

$Y$, sin embargo, Jesús muere ejecutado por las autoridades estatales, judías y romanus, en Jerusalén. Anle esa ejecución, podría pensarse que el proyecto de Dios ha fracasado. Que Dios no ha iniciado realmente su reinado de justicia. Aparentemente. Dios no ha escuchado las peticiones de Jesús en el huerto, ni ha hecho justicia a sus elegidos, que claman a él noche y día (Lc 18,7). Sin cmbargo, la le de la comunidad cristiana va a proclamar todo lo contrario: en Cristo se ha hecho posible de un modo inusitado la realización de la justicia en este mundo.

\section{5. "La justicia que es por fe"}

Descle el punto de vista de las primeras comunidades cristianas, la muerte de Cristo en la cruz forma parte de una buena noticia: la buena noticia de que ahora es posible realmente la verdadera justicia, con independencia de la ley de Moisés (Ro 3. 21). Por lo general, esto se ha entendido en términos más bien individualistas, y se ha referido con frecuencia al más allá. Pero no es esto lo que los escritores del Nuevo Testamento quieren decir. Se trata más bien de todo lo contrario: lo que el Nuevo Testamento proclama es que aquello que no pudo haccr la ley de Israel, es ahora posible por medio de Jesucristo. Y, como vimos, lo que pretendía la ley de Israel era constituir un pueblo distinto, en el que se realizara la justicia, para fascinar y atraer hacia así a todos los pueblos de la lierra. Por eso mismo, la justicia de la que habla el Nuevo Testamento no es primeramente una exigencia ética, sino una buena noticia: la buena noticia de que en Cristo se ha revelado de modo definitivo la justicia de Dios (Ro I, 16- 
17). $Y$ esta justicia no es para el otro mundo, sino que ha comenzado ya en la historia, y se está realizando ya en las comunidades cristianas (Ro 5,17 ).

El que se realice en las comunidades cristianas, y no en el Estado romano o judío, es algo que se explica por el hecho de que la justicia de la que nos habla el Nuevo Testamento sólo es posible por la fe. Para explicar esto, Pablo acude en ocasiones al relato de "Adán": la lógica propia de Adán ha sido cancelada por Cristo, el nuevo Adán (1Co 15, 45). La lógica propia de "Adán", es decir, la lógica propia del ser humano fuera de la fe, es la lógica de la aulojustificación. Es la pretensión de justificarse a uno mismo por los resultados de las propias acciones. Desde este punto de vista, Dios aparece como aquel que garantiza que cada uno reciba el resultado merecido de sus acciones. Esto no implica sólo que los buenos son premiados y los malos castigados. Esto implica también que los que aparentemente son castigados, es porque algo han hecho. Es el problema con el que se enfrentaba Job. Con Cristo, esta lógica ha sido cancelada de forma definitiva, porque Cristo aparentemente fue abandonado por Dios y castigado (G) 3, 13; 2 Co 5, 21). Sin embargo, Dios estaba en Cristo, reconciliando al mundo consigo (2 Co 5, 19), y por ello, la muerte no pudo retener a Jesús. Y esto no sólo significa que Dios se ha solidarizado con todas las víctimas de la historia, con todos los aparentemente rechazados por Dios. Esto significa, además, que Dios ha anulado la idea de una correspondencia entre nuestras acciones y sus resultados, y con ello, la vana pretensión de justificarnos por los resultados de nuestras acciones. $Y$ esto entraña, al mismo tiempo, la victoria ya lograda de Cristo sobre todos los poderes económicos, políticos o religiosos que, como la serpiente, pretenden garantizarnos una correspondencia entre nuestras acciones y sus resultados: Dios "canceló la nota de cargo que había contra nosotros, la de las prescripciones con sus cláusulas desfavorables, y la quitó de en medio clavándola en la cruz. Y, una vez despojados los principados y las potestades, los exhibió públicamente en su cortejo triunfal"' (Col 2, 14-15).

Lo que esto quiere decir es que Dios nos ha concedido de modo gratuito la justificación, no como resultado de nuestros esfuerzos, sino por la fe (Ro 3,21 ). La justicia de Dios consiste en habernos dado la fe (2P I, I), y la fe nos alcanza la justicia. Esta justicia no es algo interior o espiritual; es, ciertamente, la justicia para con Dios, pero también es la justicia social, que ahora se realiza en las comunidades cristianas. Lo que Israel no pudo alcanzar, la abolición de la pobreza (Dt 15,4 ), lo pueden alcanzar las comunidades cristianas cuando se edifican sobre la fe (Hch 4, 34). La necesidad de la fe reside en el hecho de que, si no nos fiamos de que Dios nos ha declarado justos gratuitamente en Cristo, haciendo inútil la pretensión de justificarnos a nosotros mismos como resultado de nuestras acciones, necesariamente seguiremos pretendiendo autojustificarnos. $Y$, si seguimos pretendiendo justificamos a nosolros mismos, seguiremos introduciendo en el mundo las consecuencias de la pretensión adámica de vivir de los resultados de las propias acciones. Seguiremos temiendo a Dios, manipulan- 
Lo a los demás para eludir nuestra responsabilidad, envidiando a otros. oprimićndolos para conseguir admiración o poder, y. en delinitiva. construyendo en la historia nuevas torres de Babel. La tierta será el escenario de nuestra sed de producir y el último resultado de nuestra vida será la muerte.

En cambio, si nos fiamos de que Dios ha anulado. mediante la vida. muerte y resurreción de Cristo, la ley de la autojustificación, podemos renunciar a la pretensión de poder y prestigio. Ya no tenemos que temer a un Dios que juzga nuestro rendimiento, sino que podemos descansar en El y llamarle confiadamenIc $A b b a$, padre (Ro 8. I5). No lendremos que desconliar del prójimo, como posible jue\% y opresor nuesiro, sino que los cristianos podremos considerarnos como hermanos y hermanas, miembros de una familia de iguales, en la que alesiparecc lodo patcrnalismo patriarcal. Los bienes de la lierta ya no cstarán al servicio de una loca carrera por producir, sino que podrán ser vueltos a dislirutar colno dones gratuitos que se pueden compartir en comunidad. Las diferencias de género ya no tendrán que entenderse en términos de dominación ni de concurencia, sino de complementariedad reconciliada. La misma muerte habrá perdido su aguijón ( $\mathrm{CO}$ 15,55), porque ya no nos amenaza con ser el último resultado de todos nucstros esluerzos. La injusticia que entrañaba la incredulidad de "Adán" es sustituida ahora por la justicia que posibilita la fe de Cristo, iniciador de nucstra propia le (Heb 12,2). Por eso mismo, la justicia bíblica cslá indisolublemente unida a la fe. No es la justicia de las obligaciones élica generaJes. sino una nueva justicia. Ya no es la propia justicia, sino la justicia que viene de la le de Crisıo, la justicia que es de Dios por la fe (Fil 3, 9).

Lo que afirma el Nuevo Testamento es la posibilidad de realizar la justicia social cn las comunidades que surgen de la fe (Hch $2,42-46 ; 4,32-37$ ). No se trata simplemente de que se satisfagan las necesidades materiales, sino de toda una nueva forma de vida, en la cual se realizan la paz, la justicia y la felicidad humana (Ro 14, 17). Y csto no es un resultado de los propios esfuerzos. sino un don del Espírilu. precisamente, porque si la fe fuera obra nuestra, podríamos gloriarnos en ella, y seguiríamos en la misma lógica de Adán (Ef 2, 8-9). Lo que sabemos históricamente de las comunidades crislianas de los tres primeros siglos es que, de hecho, ellas realizaron, con todas las limitaciones que se quiera, una forma de vida alternativa, en la que no sólo era superada la pobreza, sino que las diferencias derivadas del género o de la condición social eran reducidas o desaparecían. Ello no se debía a que las comunidades cristianas pretendieran conquistar el palacio del emperador romano o el de Herodes o el de Caifás, para más adelante realizar desde allí reformas sociales. El atractivo y la peligrosidad de las comunidades cristianas consistía en que ellas, de hecho (no como ideología), desde la hase (y no desde palacios presidenciales) y desde el presente (y no como promesa futura) realizaban ya la nueva justicia, proclamando que ellas estaban bajo una nueva soberanía: bajo la soberanía de Cristo, quien de esta manera ejerça ya en la historia el reinado de Dios (Hch 17,6-8). La oración de 
los cristianos por las autoridades tiene este sentido: pedir que ellas les permitan realizar su nueva forma de vida alterantiva (ITi 2, 1-2). Precisamente, porque la justicia era una realidad, los apologetas cristianos, como Justino, pudieron afirmar frente al judaísmo que había pruebas concretas de que el mesías ya había venido, y que ese mesías era Jesús. Las promesas proféticas para la era mesiánica, en la que habría de desaparecer la violencia y la injuslicia (Is 11, 1 $9)$. se estaban realizando ya en las comunidades cristianas.

\section{El presente de la justicia}

$\mathrm{Si}$ ahora tratamos de llevar estas enseñanzas biblicas al presente, hemos de comenzar reconociendo que, con demasiada Irecuencia, los cristianos siguen pensando que la clave para instaurar la justicia social consiste en la toma del palacio del Taraón por un grupo político adecuado. No cabe duda que no es indiferente quién ocupe el poder político, en cada momento de la historia. El laraón que acogió a José y sus hermanos es muy distinto del faraón (¿Ramsés II?) que impuso a los israelitas una dura servidumbre. No lodos los emperadores se comportaron de la misma manera ante el desafío de las comunidades cristianas. Sólo este hecho hastaría para justificar una profundo interés de los cristianos por la política. No se trata, obviamente. de un interés sectario o egoísta. como podría suceder cuando, por ejemplo, en determinadas iglesias, el clero deliende sus propios intereses económicos, o sus propias instituciones educativas. Lo que está en juego es algo muy distinto. Y es que las comunidades cristianas, cuando son verdaderas iglesias, constituyen por $s i$ mismas las primicias de una nueva humanidad, el lugar donde la juslicia de Dios comienza a irrumpir en la historia. En este sentido, el interés por la transformación de toda la humanidad exige el interés por la viabilidad histórica de unas comunidades, en las cuales ya se han iniciado las novedades propias de la era mesiánica. Si los cristianos aspiran a realizar la justicia en la historia, tienen que asegurar la posibilidad de que ya hoy, en nuestro mundo, sea visible una alternativa a las profiundas injusticias que lo atraviesan.

Esto signilica, entonces. que el modelo de José-Daniel-Ester sigue siendo un punto de referencia válido para considerar las posibles actuaciones políticas de los creyentes. También en el Nuevo Teslamento aparece algún creyente que ocupa un cargo público en su ciudad (Ro 16, 23). Sin embargo, convicne entender correctamente el sentido de estas actuaciones. Cuando ellas tienen un senti(lo teologal más allá de la simple ocupación laboral, éste consiste en el servicio que desde los diversos cargos políticos se puede prestar a la pervivencia del puchlo elegido por Dios, porque este pucblo, en cuanto sociedad altcrnativa, está cusi continuamente amenazado por los imperios bestiales, a los cuales su mera existencia cuestiona (Dn 7, 15-28). Por supuesto, esos cargos públicos existen en lunción de intereses propios del Estado en cuestión, y esto entraña la posibilidad de prestar, desde ellos, grandes servicios a la vieja sociedad. tal como mues- 
tra, por ejemplo, la actuación política de José en Egipto. El amor cristiano se dirige a todos, por más que la comunidad alternativa no se construya con todos (Lc 10, 25-37; Gl 6, 10). En cambio, lo que contradice frontalmente el testimonio bíblico es la tendencia ingenua, y en el fondo conservadora, a pensar que los cambios políticos hechos desde los diversos palacios imperiales constituyen el inicio del reinado de Dios en la historia. Tendencia ingenua, porque ignora la naturaleza constitutivamente violenta de todo Estado; y conservadora, porque renuncia a los cambios verdaderamente radicales, consolidando el sistema político, en lugar de afirmar, como Daniel, su radical caducidad (Dn 2, 37-45). Además, no hay que olvidar que el ejercicio de tales funciones suele exigir comportamientos muy poco compatibles con la fidelidad exclusiva al Dios cristiano. Los poderosos con frecuencia se sienten inclinados a asegurar la fidelidad de sus colaboradores, pidiendo de ellos no sólo juramentos, sino también incluso el culto idolátrico a su persona. El creyente que asume responsabilidades públicas sin renunciar a su fe no ha de olvidar las muchas posibilidades que tiene de acabar en el foso de los leones o, al menos, como Ester, en el harén del emperador.

Lo decisivo de la acción de Dios está en otra parte: en aquellas comunidades que permiten que Dios reine y sea Señor sobre ellas, desterrando a los ídolos y comenzando ya una nueva sociedad. Esta es la verdadera "política": la Tormación de asambleas (ekklesíai) de personas libres, en las cuales desaparecen las diferencias económicas y sociales. En la Iglesia cristiana, como nueva convocación de Israel (qahal), y a diferencia de las asambleas de la polis griega, participaban las mujeres y los esclavos, mostrando la posibilidad de una sociedad nueva. Lamentablemente, muchos líderes religiosos prefieren hoy dedicar sus encrgías a la polis establecida, y no al servicio de las comunidades alternativas. En el extremo, se llega a predicar a los poderosos, que tienen que organizar sus sociedades de forma distinta sin que existan comunidades cristianas que puedan mostrar que, por la gracia de Dios, es posible vivir de otra manera. El agotamiento de muchas comunidades de base tiene su causa última en este desequilibrio fatal. En cierto modo, para los líderes religiosos puede resultar más cómodo denunciar las responsabilidades de los poderosos, en lugar de ver cuántos panes uno mismo tiene en la propia bolsa, no para repartirlos paternalmente, sino para ponerlos a disposición de lodos, en un banquete de iguales. En el evangelio, mucho más importante y radical que el "anuncio y la denuncia", es la primaria y decisiva renuncia a los bienes. Sin ella, no hay sociedad alternativa. Por eso mismo, la renuncia a los bienes no se predica primeramente a Herodes o a César Augurto, sino que se exige simple y llanamente del discípulo, que quiere seguir a Cristo y formar parte de su comunidad.

La gran cuestión de la justicia se juega en la disponibilidad que los cristianos tcngan en el presente de permitir que el Espíritu forme comunidades mesiánicas. donde se muestre la posibilidad de una alternativa al sistema. De hecho, siempre 
que el Espíritu actúa en las iglesias aparecen comunidades de este tipo, más o menos logradas, y por más que las estridencias de la cultura religiosa popular no siempre agraden a los teólogos. Siempre ha sido así en la historia de la glesia cristiana, en todas sus confesiones. Sin embargo, un pertinaz constantinismo sigue haciendo pensar a muchos que el lugar por excelencia del cambio social no es otro que la sociedad en su conjunto. Desde el siglo IV, muchos tienen la idea de que toda la sociedad es o debe ser, de algún modo y casi por naturaleza, cristiana. En América Latina la conquista significó una brutal continuación de este constantinismo, de modo que muchos, todavía en el siglo $\mathrm{XX}$ siguen hablando de un "continente cristiano", a pesar de las flagrantes injusticias, de la evangelización muchas veces sólo impuesta y aparente, de la progresiva secularización y de las profundas divisiones religiosas. Pero los continentes no son cristianos, sólo las personas y las comunidades. En la mentalidad constantiniana, como todos son presuntamente cristianos, todos forman parte del pueblo de Dios, y todos están llamados a transformarse en una sociedad según el modelo del Exodo y del evangelio. Este modo de pensar, aunque puede inspirar algunas Incjoras cosméticas en el sistema, está incapacitado para presentar alternativas verdaderamente radicales a la civilización imperante del capital. La sociedad en su conjunto no puede regirse por ideales que exigen la salida del sistema y que solalnente son posibles, por tanto, desde la libertad de la fe. Cuando se pretende lalsamente que lodos son cristianos, no queda más remedio que rebajar las exigencias radicales del cristianismo, para convertirlo en una ética social, aplicable a todos. Finalmente, sólo se pide que los poderosos, como Hammurabi, se acuerden del huérfano y de la viuda. En este esquema, caben fases de enfrentamiento entre cl trono y el altar, pero estos episodios serán necesariamente breves. porque tanto el trono como el altar seguirán siendo parte de un sistema social, donde no se ha introducido novedad alguna. Los intereses comunes, desde la educación hasta las ceremonias públicas, los volverán a sentar en la misma mesa.

La fe y la justicia sólo son una novedad transformadora allí donde ellas ya están realmente actuando, mostrando, mediante la existencia de unas comunidades alternativas, la posibilidad de otra forma de vida. No tiene mucho sentido peclir que el faraón, Herodes o Caifás se comprometan con la justicia social al mismo tiempo que se sigue viviendo en instituciones que comparten la misma lógica y las mismas formas de gobierno que rigen en el sistema social en su conjunto. Una lucha por la justicia que se realiza de esta manera sólo podría presentar, con la amargura de lo imposible, ciertas exigencias éticas generales, pero no una verdadera alternativa. En una fase del capitalismo mundial como la que actualmente estamos viviendo, son más necesarias que nunca las alternativas reales y visibles, y no las simples invocaciones moralizantes a la justicia. Incluso quienes desde un pensamiento secular buscan alternativas al sisteına dominante confluyen en afirmar la necesidad de iniciar desde la base nuevas 
lormas económicas. Desde una perspectiva cristiana, esto es lo que posibilita la le. Los cristianos pueden darle al mundo la buena noticia de que otra forma de vida ya es posible, y está en marcha en la historia. Por eso mismo, muchas iglesias y comunidades requieren una profunda conversión, pues ellas comparten la misma lógica autoritaria y desigual con los grupos más conservadores de la sociedad. O con grupos que, presentándose como progresistas, nadie los puede percibir ya como verdadera alternativa, porque no realizan la justicia en su interior.

En un mundo desencantando como el actual, en un mundo donde, como decía Casaldáliga, la milad de la población muere de hambre y la otra mitad de ıniedo a la muerte, es más necesario que nunca presentar alternativas rcales, y no sólo discursos éticos generales o competencias por el poder. Ni Herodes, ni Cailás, ni Espartaco, ni Barrabás, ni ningún faraón multinacional va a cambiar signilicativamente el mundo hacia la justicia. El mundo se cambia allá donde la muertc y la resurrección de Cristo inician realmente una forma de vida alternativa, capaz de mostrar la falsedad del sistema dominante y la viabilidad de unas relaciones humanas distintas. La aparición de pequeños faraones, de reyes-saccrdoles de izquierdas no es una buena noticia que desestabilice el sisterna o que atraiga hacia sí a los empobrecidos. Lo que cambia al mundo de un modo electivo es la aparición de comunidades en las cuales comienzan, por la fe, unas nueves rclaciones de justicia. La buena noticia es que esas comunidades, a pesar Jc la desobediencia de los cristianos a lo largo de la hisloria, nunca han desaparecido del todo, y que el Espíritu las sigue creando allí donde los creyentes escuchan con oídos libres la palabra de vida. El Exodo tiene lugar en la actualiclad y sigue siendo posible para los cristianos. En cllo no sólo se juega un proyecio de carnbio social, sino algo más radical. Y es que, si el inesías realmente ha venido, ya tiene que haber en el mundo una sociedad distinta. La alternativa más decisiva no cstá entre las izquierdas y las derechas. entre laraones buenos y malos. La alternativa verdaderamente decisiva se da entre el muro de las lamentaciones y la afirmación gozosa de que el mesías ya ha venido y reina como Señor sobre su pequeño pueblo. 